\title{
Computational fluid dynamics of computed tomography angiography to detect the hemodynamic impact of intracranial atherosclerotic stenosis
}

Xinyi Leng ${ }^{1}$, Fabien Scalzo ${ }^{2}$, Albert K Fong ${ }^{2}$, Mark Johnson², Hing Lung I I ${ }^{1}$, Yannie Soo ${ }^{1}$, Thomas Leung ${ }^{1}$, Liping Liu ${ }^{3}$, Edward Feldmann ${ }^{4}$, Ka Sing Wong ${ }^{1}$ and David S Liebeskind ${ }^{2,5^{*}}$

\begin{abstract}
Background: In symptomatic intracranial atherosclerotic stenosis (ICAS), its hemodynamic impact may affect the risk of stroke recurrence, in addition to the degree of luminal stenosis. We therefore conducted a pilot study to evaluate the feasibility to delineate the hemodynamic impact of symptomatic ICAS lesions using computational fluid dynamics (CFD) models reconstructed based on computed tomography angiography (CTA) source images.

Methods: Three-dimensional CFD models were reconstructed based on routine CTA source images of patients with a symptomatic ICAS lesion. The anatomic features and hemodynamic impact of target ICAS lesions were evaluated on the CFD models. The hemodynamic impact of a lesion was evaluated using distal to proximal pressure ratio (PR) and pressure gradient (PG) across the lesion. PG was defined as pressure drop across the lesion divided by length of the lesion.

Results: Among the 10 cases recruited, CTA source images of 9 cases were successfully processed to CFD models. The hemodynamic characteristics of the ICAS lesions could be quantitatively evaluated on the CFD models, such as the pressures, blood flow velocities, wall shear stress and shear strain rates. The median PR was 0.58 and the median PG was $93 \mathrm{mmHg} / \mathrm{cm}$. PRs and PGs varied in cases with similar degrees of stenoses with different lesion lengths and proximal vessel diameters.

Conclusions: This pilot study demonstrated the feasibility to quantitatively assess the hemodynamic impact of ICAS using CFD models reconstructed based on routine CTA. Further studies are required to improve the models built in this pilot study, and to evaluate the ultimate value of this technique in clinical assessment and risk stratification of patients with symptomatic ICAS.
\end{abstract}

Keywords: Cerebral hemodynamics, Cerebrovascular disease, Stroke, Computational flow dynamics, Computed tomography angiography

\section{Background}

As the most common cause of ischemic stroke and transient ischemic attack in Asian populations and an important cause of stroke as well in other populations, intracranial atherosclerotic stenosis (ICAS) has attracted attention both in clinical practice and relevant research fields in recent decades [1-3]. The degree of anatomic stenosis was

\footnotetext{
* Correspondence: davidliebeskind@yahoo.com

${ }^{2}$ UCLA Stroke Center, University of California, CA 90095 Los Angeles, USA

${ }^{5}$ UCLA Department of Neurology, Neuroscience Research Building, Suite 225,

Los Angeles, CA 90095-7334, USA

Full list of author information is available at the end of the article
}

noted as an independent predictor for recurrent ischemic $s$ troke $i$ n the territory of the index artery (SIT), for instance, in the Warfarin-Aspirin Symptomatic Intracranial Disease (WASID) trial [4]. However, the fact also existed that nearly half of the SIT occurred in patients with 50-69\% ICAS in the WASID trial [4]. According to the Chinese IntraCranial AtheroSclerosis Study, recurrent stroke also occurred in a considerable percentage of patients with $<50 \%$ ICAS [5]. On the other hand, factors affecting hemodynamics of ICAS, for instance, collateralization, have been found to dramatically alter subsequent 
stroke risks in the WASID and the Stenting and Aggressive Medical Management for Preventing Recurrent stroke in Intracranial Stenosis (SAMMPRIS) trial [6,7]. Therefore, hemodynamics plays an important role in the case of ICAS, concerning subsequent risk of SIT. Evaluation of hemodynamic impact of ICAS will probably facilitate in the risk stratification of patients with symptomatic ICAS.

Computational fluid dynamic (CFD) techniques, when applied in simulation of blood flow, can quantitatively reveal hemodynamic characteristics of arterial stenosis. Noninvasive fractional flow reserve (FFR), which is the distal to proximal pressure ratio (PR) across a stenosis, measured through CFD reconstruction of coronary computed tomography angiography (CTA), has been identified of high diagnostic accuracy for the hemodynamic significance of stenosed coronary arteries as compared with FFR obtained invasively, and this is promising in guiding patient selection for percutaneous coronary intervention [8,9]. More recently, virtual FFR obtained from CFD models based on coronary angiograms by assigning averaged generic downstream boundary conditions without simulating hyperemic conditions, was also found to be substantially accurate to define hemodynamically significant coronary lesions (accuracy of 97\%), as compared with invasively measured FFR under induced hyperemia [10]. In addition, CFD could also be used to reveal the hemodynamic effects of ICAS $[11,12]$. In the present pilot study, we evaluated the feasibility to discern hemodynamic impact of ICAS using CFD models reconstructed from routinely obtained CTA images with a small sample size, to pave the way for generalized application of this technique in larger clinical studies in the near future.

\section{Methods}

\section{Subjects}

This was a retrospective observational study. Ten patients, each with a symptomatic ICAS lesion (50-99\% luminal stenosis, WASID criteria [13]) of a major intracranial artery [intracranial portion of internal carotid artery (ICA); M1 segment of middle cerebral artery (MCA-M1); or basilar artery (BA)] identified on CTA, were retrospectively selected from a prospective clinical study at Prince of Wales Hospital in Hong Kong. All patients had given written informed consent for the previously approved prospective clinical study, and the current retrospective study was also approved by the Joint Chinese University of Hong Kong-New Territories East Cluster Clinical Research Ethics Committee (the Joint CUHKNTEC CREC). Patients' characteristics were collected from clinical records. CTA source images were retrieved and anonymized from the picture archiving and communication system and transferred to University of California, Los Angeles for reconstruction of CFD models.

\section{CT protocol}

All CT examinations were performed on a 64-slice CT scanner (Lightspeed VCT, GE Healthcare, US), including non-contrast CT scan of the whole brain and CTA of intracranial arteries. The non-contrast CT scan was performed in axial mode, covering the skull base to vertex region, and obtained at $120 \mathrm{kV} 320 \mathrm{~mA}$ and $1.0 \mathrm{sec}$ rotation. CTA was performed in helical mode with no tilting, covering the skull base to the level of lateral ventricles, and obtained at $120 \mathrm{kV} 550 \mathrm{~mA}$ and $0.4 \mathrm{sec}$ rotation. Intravenous contrast ( $70 \mathrm{ml}$ Omnipaque $300,3-3.5 \mathrm{ml} / \mathrm{s}$ ) was injected via the antecubital vein using a power injector. Axial CTA images were reconstructed at $0.625 \mathrm{~mm}$ intervals and stored as source images for further image analysis.

\section{CFD simulations of hemodynamics}

The scientific basis of evaluating hemodynamics of ICAS lesions, such as the trans-stenotic pressure gradient, using simulated models constructed out of standard CTA source images, was that the hemodynamic features of such lesions could be calculated via the CFD technique by applying several assumptions on the three-dimensional (3D) vessel geometry obtained from CTA source images. CFD simulations of hemodynamics were performed through the following procedures. Firstly, the location of the target arterial segment was visually identified and delineated with a region-of-interest on CTA images. The region-of-interest was then segmented using a gradientdriven level set method [14] to extract the vascular volume. Centerlines were then computed from selected inlet and outlet points placed at the extreme points of the vessel. The diameter of the vessel along the centerline was derived using the Voronoi method which allowed a 3D geometry of the vessel to be constructed. A mesh of the 3D surface was then created using ANSYS ICEM-CFD (ANSYS, Inc.), composed of approximately 500,000 tetrahedral cells. Blood flow simulation was then performed on this mesh using ANSYS CFX software. It was assumed that blood was an incompressible Newtonian fluid with a constant viscosity of $0.004 \mathrm{~kg} \mathrm{~m}^{-1} \mathrm{~s}^{-1}$ and could be governed by the Navier-Stokes equations [15]. It was also assumed that blood has a density of $1060 \mathrm{~kg} / \mathrm{m}^{3}$. The boundary conditions placed on this simulation was one that assumed rigid, non-compliant walls with no-slip flow conditions. The inlet boundary condition was set to be $120 \mathrm{mmHg}$ while the outlet velocity was prescribed as $60 \mathrm{~cm} / \mathrm{s}$. As it has been assumed that the vessel is non-compliant, the velocity downstream can be assumed to also follow ideal pipe-flow and thus physiological velocities. The simulation results were post-processed in ANSYS CFX-post (ANSYS, Inc.), for extraction of flow parameters, for instance, velocity, pressure, wall shear and shear strain rates (Figure 1). 


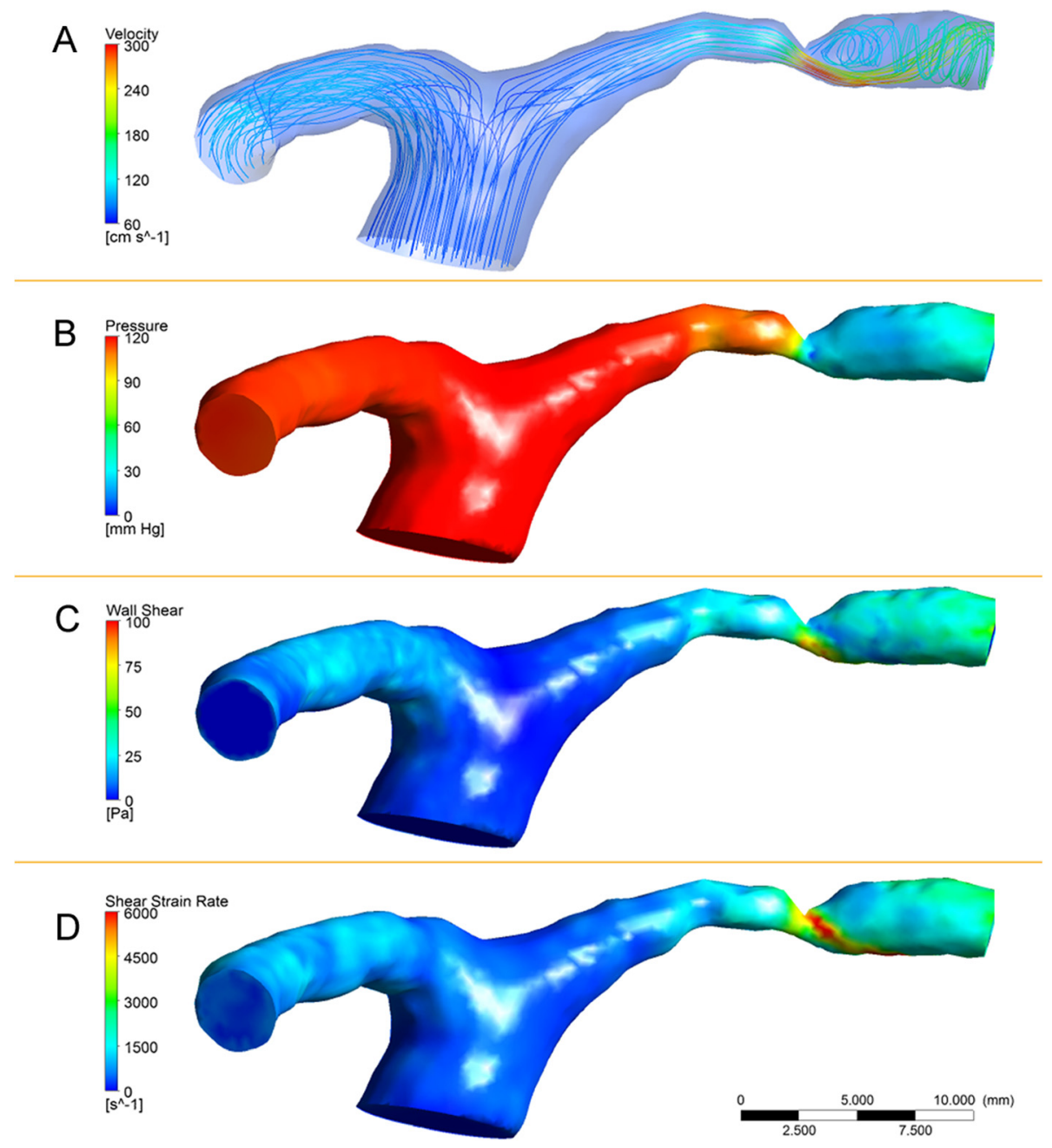

Figure 1 The CFD model showing hemodynamic characteristics of a 70\% MCA-M1 stenosis (Case \#4). Blood flow velocity (A), wall shear stress $(\mathbf{C})$ and shear rates (D) dramatically increased and pressure (B) greatly decreased in situ and downstream to the lesion. Besides, turbulence and a recirculating flow was noted immediately distal to the ICAS lesion (panel A). CFD indicates computational fluid dynamics; MCA-M1, M1 segment of middle cerebral artery.

Generation of mesh, simulation of blood flow and postprocessing of simulation results were run on a Cray CX1 cluster (Cray Inc.).

\section{Measurement of anatomic characteristics of ICAS}

Proximal normal vessel diameter, anatomic severity, and length of the stenoses were measured on reconstructed 3D models. Anatomic severity of ICAS was measured according to the WASID criteria [13]. Length of a lesion was defined as the distance between the first normal diameters distal and proximal to the stenosis.

\section{Evaluation of hemodynamic impact of ICAS}

Evaluation of the CFD models was also performed in ANSYS CFX-post (ANSYS, Inc.). Hemodynamic impact of ICAS was evaluated by using 2 indices in the present study, which were PR and pressure gradient (PG) across the lesion. Pressures were measured at the 1st normal diameters distal and proximal to the lesion, for which spherical volumes-of-interest with the same radius of the vessel were selected within the vessel domain to get the mean pressure value. PR was defined as the distal to proximal pressure ratio, and PG $(\mathrm{mmHg} / \mathrm{cm})$ was defined as pressure drop across the ICAS divided by length of the lesion. Since this was a preliminary study, and that there had been no data about the cut-point value of PR to define a hemodynamically significant ICAS, we used the same cut-point of PR (0.80) as is used in the cardiac field for FFR [16], with a PR less than or equal to 0.80 considered hemodynamically significant in the present study. 


\section{Statistical analysis}

Descriptive statistics were used in the current study to describe demographics of patients recruited and imaging characteristics of the symptomatic ICAS lesions.

\section{Results}

Among the 10 patients recruited in this study, the CTA source images of 9 subjects (median age was 62, and 7 were males) were successfully processed to CFD models. In the other one case, vessel geometry of the arterial segment containing the ICAS lesion failed to be extracted from the CTA source images due to poor image quality. The reconstructed CFD models could quantitatively depict hemodynamic environment at the stenosis. Blood flow velocity, wall shear stress and shear rates increased and pressure decreased in situ and downstream to a stenosis. Figure 1 shows hemodynamic characteristics of a 70\% MCA-M1 stenosis (Case \#4), revealed by the CFD model.

Among the 9 cases processed, 7 were MCA-M1 lesions, and the other 2 were ICA and BA lesions, respectively. Four cases were $70-99 \%$ stenoses. Patient demographics, anatomic characteristics of ICAS, and other parameters and indices measured and calculated from the CFD models are shown in Table 1. The median PR was 0.58 and the median PG was $93 \mathrm{mmHg} / \mathrm{cm}$. Four anatomically severe and 1 anatomically moderate stenoses were considered hemodynamically significant $(\mathrm{PR} \leq 0.80)$ in the current study. Besides, PRs and PGs varied in cases with similar percentages of stenoses (Table 1 and Figure 2). For instance, Case \#5, \#6 and \#7, with similar anatomic severity of stenoses (around 80\%) in MCA-M1 but different lesion lengths and proximal vessel diameters, greatly differed in hemodynamic severities as assessed via CFD models (Table 1). The pressure maps of Case \#6 and \#7 are shown in Figure 2, with PGs of 300 and $5,382 \mathrm{mmHg} / \mathrm{cm}$, respectively.

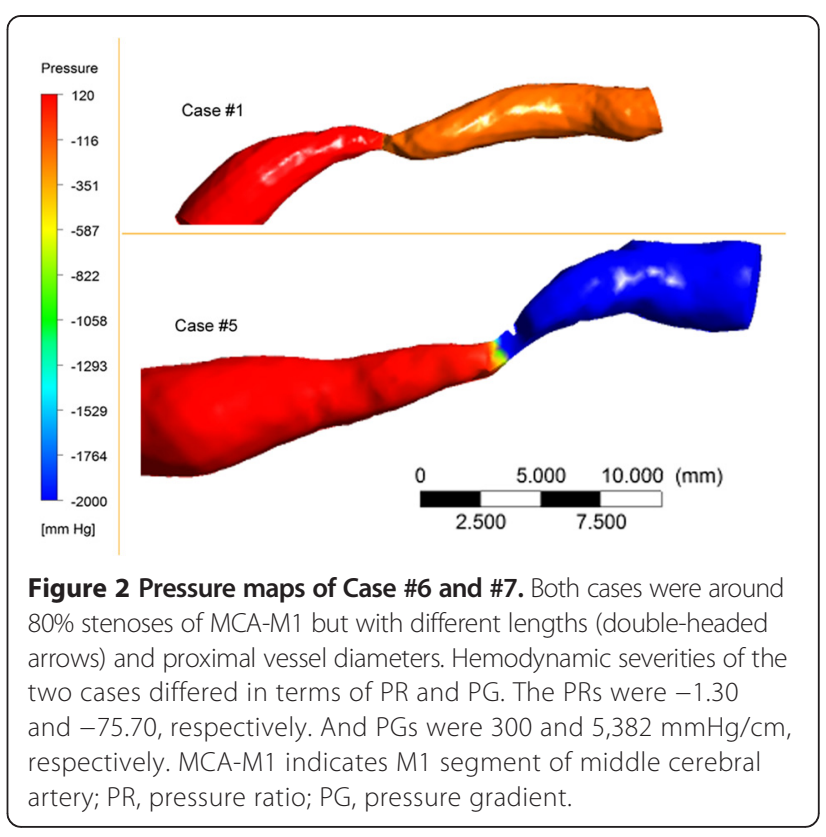

\section{Discussion}

This was a feasibility study. Despite of the small sample size, we demonstrated the feasibility of simulating blood flow across ICAS lesions by CFD modeling based on routinely obtained CTA images, and the feasibility of quantitatively analyzing the hemodynamic characteristics of such lesions on the CFD models. Besides, the study results implied that the severity of luminal stenosis probably was not the only indicator to determine the hemodynamic impact of symptomatic ICAS lesions, which reinforced the urgent need for a more comprehensive paradigm for clinical evaluation of such lesions, to replace, or at least improve, the current unreasonable and misleading method of defining the significance of such lesions only based on the percentage of stenosis.

Table 1 Patient demographics and ICAS characteristics*

\begin{tabular}{|c|c|c|c|c|c|c|c|c|c|c|}
\hline \multirow[t]{2}{*}{ Patient \# } & \multirow[t]{2}{*}{ Gender } & \multirow[t]{2}{*}{ Age } & \multicolumn{3}{|l|}{ ICAS } & \multirow{2}{*}{$\begin{array}{l}\text { Proximal } \\
\text { vessel diameter } \\
(\mathrm{mm})\end{array}$} & \multirow{2}{*}{$\begin{array}{l}\text { Proximal } \\
\text { pressure } \\
(\mathrm{mmHg})\end{array}$} & \multirow{2}{*}{$\begin{array}{l}\text { Distal } \\
\text { pressure } \\
(\mathrm{mmHg})\end{array}$} & \multirow{2}{*}{$\begin{array}{l}\text { Pressure } \\
\text { ratio }\end{array}$} & \multirow{2}{*}{$\begin{array}{l}\text { Pressure } \\
\text { gradient } \\
(\mathrm{mmHg} / \mathrm{cm})\end{array}$} \\
\hline & & & Location & $\begin{array}{l}\text { Anatomic } \\
\text { severity (\%) }\end{array}$ & $\begin{array}{l}\text { Length } \\
(\mathrm{mm})\end{array}$ & & & & & \\
\hline 1 & $M$ & 44 & MCA-M1 & 50 & 20 & 3.5 & 118 & 104 & 0.88 & 7 \\
\hline 2 & $M$ & 68 & MCA-M1 & 51 & 11 & 2.7 & 118 & 107 & 0.91 & 10 \\
\hline 3 & $M$ & 51 & MCA-M1 & 53 & 13 & 2.9 & 119 & 102 & 0.86 & 13 \\
\hline 4 & $M$ & 61 & MCA-M1 & 70 & 10 & 2.7 & 120 & 29 & 0.24 & 93 \\
\hline 5 & $F$ & 74 & MCA-M1 & 78 & 14 & 3.0 & 119 & -184 & -1.55 & 223 \\
\hline 6 & $F$ & 65 & MCA-M1 & 79 & 9 & 2.5 & 120 & -156 & -1.30 & 300 \\
\hline 7 & $M$ & 62 & MCA-M1 & 80 & 17 & 3.5 & 117 & $-8,847$ & -75.70 & 5,382 \\
\hline 8 & $M$ & 69 & ICA distal & 50 & 10 & 4.2 & 120 & 118 & 0.98 & 2 \\
\hline 9 & $M$ & 50 & BA & 62 & 5 & 3.4 & 116 & 67 & 0.58 & 98 \\
\hline
\end{tabular}

*Patients are listed in the table by the lesion location and sequentially arranged according to the degree of luminal stenosis (\%) of the lesions. ICAS indicates intracranial atherosclerotic stenosis; MCA-M1, M1 segment of middle cerebral artery; ICA, internal carotid artery; BA, basilar artery. 
Patients with symptomatic ICAS are at high risk of recurrent ischemic stroke, despite of medical and/or interventional treatment [17-19]. However, commonly used noninvasive imaging modalities have been found of relatively low positive predictive values for diagnosis of 50-99\% intracranial stenosis, compared with digital subtract angiography (DSA) [20,21]. Moreover, the percentage of stenosis itself, even when diagnosed by DSA, was not the only factor that might be able to affect downstream hemodynamics in the case of ICAS. Irregularity and eccentricity of the lesion, which in many cases is influenced by the plaque compositions, as well as the collateral status, may also affect the hemodynamic impact of an ICAS lesion [22]. This may partly explain why patients with ICAS of moderate luminal stenosis would also be at risk of SIT $[22,23]$. Therefore, we aimed to evaluate hemodynamic impact of ICAS via reconstructed CFD models in the present study, which was found feasible using routinely obtained CTA source images, so that this single noninvasive imaging modality could provide much more information of ICAS beyond the anatomic severity of luminal stenosis.

Although biplane DSA images could also be used to reconstruct CFD models of ICAS [24], and that CTA may not be as accurate as DSA to depict the vessel geometry in ICAS [21], we assumed that CTA images would be a better source for CFD modeling of ICAS lesions from both the technical and clinical points of view. On one hand, CTA source images, with its threedimensional nature, yield a better source for CFD modeling than biplane DSA images, from the technical angle. On the other hand, as a noninvasive imaging modality, CTA is more commonly used and easier to be obtained in clinical practice than DSA, which permits studies with relatively large sample sizes in the future. In addition, although the noninvasive time-of-flight MR angiography can also provide three-dimensional geometry of the cerebral vessels of interest as CTA does, vessel geometry obtained from CTA is more accurate than that from MR angiography, especially in cases with extremely low distal flow beyond the ICAS lesion when MR angiography could overestimate the degree of stenosis.

Hemodynamic impact of ICAS was assessed using PR in our study, paralleled to FFR in the cardiac field, with lower PR indicating more significantly decreased downstream flow. To our knowledge, there had been no data about the cut-point of simulated PR to define a hemodynamically significant ICAS. However, for coronary artery disease, virtual FFR based on CFD models of coronary lesions had been found to be closely correlated with FFR measured under induced hyperemia during percutaneous coronary angiography (correlation coefficient $r=0.84$ ), and to be able to accurately identify lesions with FFR $<0.80$ as mentioned above [10]. Thus for this pilot study, we used the same cut-point of PR (0.80) as is currently used in the cardiac field for invasively measured FFR and virtual FFR $[10,16]$. But in future studies, we will explore an optimal cut-point of PR to dichotomize ICAS lesions by the hemodynamic impact, for instance, by comparing PR values against brain perfusion results such as quantitative arterial spin labeling MR perfusion imaging. According to the results, distal pressures and PRs of ICAS lesions were in minus values in some cases. This was one of the limitations of CFD modeling in the current study that is further discussed below, and also one of the reasons that we also used another index, PG, to quantify the hemodynamic severity of ICAS.

In the measurement of invasive FFR for coronary artery disease, use of vasodilator could decrease the microcirculatory resistance, magnify the function of existing collaterals, and hence induce hyperemia, under which circumstance the hemodynamic impact of the lesion could be accurately evaluated in most cases [25]. However, it has also been recognized that the invasive FFR might not be reliable in cases with microvascular damage, in which cases maximal hyperemia could not be achieved [10]. In a latest study as mentioned above utilizing the CFD modeling technique to obtain virtual FFR of coronary lesions, generic downstream boundary conditions, including the microvascular resistance and compliance values, were developed and applied to the arterial outlet(s) with a Windkessel model $[10,26]$. The virtual FFR obtained in this way, not affected by the status of microcirculation and without the need of simulating hyperemic conditions, was proved of substantial consistency with invasively measured FFR, with an average absolute error of \pm 0.06 [10]. Therefore, virtual fractional flow of arterial stenosis based on vessel geometry and generic boundary conditions is potentially reliable in defining the hemodynamic significance of the lesion. In the current study, we did not take into account the effects of distal microvascular resistance and the collaterals in the CFD models of ICAS lesions, which needs to be addressed in future studies, probably by referring to the method for obtaining virtual FFR for coronary lesions as discussed above.

Fractional flow across ICAS, in terms of PR and PG in our study, was not exclusively determined by percentage of the stenosis. Other morphological characteristics of an ICAS lesion might also impact on the hemodynamic environment in situ and downstream, for instance, length of the lesion as implied by this study, though we did not do any statistical analysis to confirm the speculation concerning the relationships between the lesion length and the hemodynamic impact of an ICAS due to the small sample size, as well as the irregularity and eccentricity of the stenosis that were not yet investigated in the current study. To date, few data existed on relationships between morphology and hemodynamics of ICAS, but length of 
carotid plaque and patent ICA vessel diameter, besides degree of stenosis, were found to be significantly related to ipsilateral intracranial blood flow in studies of carotid stenosis [27]. Based on vessel geometry and therefore harboring all morphological information of a lesion, simulated CFD blood flow models could comprehensively reflect effects of morphological factors on hemodynamic characteristics of ICAS. Since risk of stroke recurrence could be altered by blood flow hemodynamics in patients with symptomatic ICAS, evaluation of CFD models, instead of using anatomic severity of luminal stenosis as almost the only imaging indicator, might play a role in risk stratification of these patients. In addition, evaluating the hemodynamic parameters embedded within the CFD models of symptomatic ICAS lesions, such as PR, PG, flow velocity, wall shear stress and shear strain rates, may be useful to embrace a better understanding of the effects of hemodynamics on diverse pathomechanisms of ICAS-related ischemic stroke, which are currently understudied.

The most important limitation of the present study was that CFD models were simplified and only based on geometry of short vessel segments containing the stenoses, trimming off artery branches and meanwhile ignoring effects of collaterals and other factors that may affect hemodynamics of the lesion. This may be part of the reasons for the minus downstream pressure values as detected in the CFD models of some cases. Besides, the prescribed outflow velocity may also partly contribute to the unrealistic minus pressures in some of the CFD models. In future studies, the following measures could be explored to improve the realistic accuracy of the simulated CFD models: covering longer vessel segments in the CFD models, at least long enough for post-stenotic blood flow to restore laminar flow; and assigning personalized pressures and flow velocities at the inlet and outlet that could be of higher physiological significance, for instance, flow velocities distal to an ICAS lesion at a major intracranial artery detected by transcranial Doppler. Moreover, unlike carotid arteries, intracranial arteries have plenty of braches and perforators, which could alter the hemodynamics of blood flow in a major intracranial artery. Therefore, including main adjacent branches and perforators in the CFD models of ICAS lesions in future studies, as what is currently done for CFD modeling of coronary lesions $[9,28]$, could further optimize the realistic accuracy of the simulating results. Also, it would further enhance the clinical relevance of CFD blood flow simulation of symptomatic ICAS by considering the effects of distal microvascular resistance and collateral status, which might also facilitate better understanding of mechanisms of collateral recruitment in the presence of symptomatic ICAS. In addition, another limitation of the current study lay in that simulated pressure gradients were not validated against direct, invasive measures, or compared with indirect measures with other noninvasive methods, which will also be addressed in future studies.

Apart from the above measures to improve the CFD models of ICAS lesions, meanwhile we also need to balance the complexity and accuracy of the models with its generalizability in clinical studies. Simplified modeling would be less time-consuming for each patient involved and probably more generalizable for large clinical studies in the future, but at the meantime the consequent inaccuracy of simulated hemodynamic environment may compromise its clinical perspective. Thus, achieving an acceptable balance between the realistic accuracy and the generalizability of CFD modeling of symptomatic ICAS lesions is important for this technique to ultimately be of clinical significance and utility in the assessment of such lesions.

\section{Conclusions}

This pilot study demonstrated the feasibility to quantitatively assess hemodynamic impact of ICAS using CFD models reconstructed from routinely obtained CTA. A vast number of studies are required to evaluate the ultimate value of this technique, to seek improvement in the realistic accuracy and the generalizability of CFD modeling of ICAS, and to explore the role of specific hemodynamic characteristics from CFD models in risk stratification of patients with symptomatic ICAS.

\section{Competing interests}

The authors declare that they have no competing interests.

\section{Authors' contributions}

$\mathrm{XL}$ contributed to study design, data collection, analysis and interpretation, and manuscript preparation; FS, AKF, MJ and HLI contributed to image processing and computational modeling; YS and TL contributed to data collection and interpretation; LL and EF contributed to study design and manuscript preparation; KSW and DSL contributed to study design, data analysis and interpretation, and manuscript preparation. All authors read and approved the final manuscript.

\section{Author details}

${ }^{1}$ Department of Medicine and Therapeutics, the Chinese University of Hong Kong, Prince of Wales Hospital, Shatin, Hong Kong SAR, China. ${ }^{2}$ UCLA Stroke Center, University of California, CA 90095 Los Angeles, USA. ${ }^{3}$ Department of Neurology, Beijing Tiantan Hospital, Capital Medical University, Beijing 100050 China. ${ }^{4}$ Department of Neurology, Tufts University, Boston MA 02111, USA. ${ }^{5}$ UCLA Department of Neurology, Neuroscience Research Building, Suite 225, Los Angeles, CA 90095-7334, USA.

Received: 8 August 2014 Accepted: 12 September 2014 Published: 21 October 2015

\section{References}

1. Wong LKS: Global burden of intracranial atherosclerosis. Int J Stroke 2006, 1:158-159.

2. Qureshi Al, Feldmann E, Gomez CR, Johnston SC, Kasner SE, Quick DC, Rasmussen PA, Suri MF, Taylor RA, Zaidat OO: Intracranial atherosclerotic disease: an update. Ann Neurol 2009, 66:730-738.

3. Saba L, Anzidei M, Piga M, Ciolina F, Mannelli L, Catalano C, Suri JS, Raz E: Multi-modal CT scanning in the evaluation of cerebrovascular disease patients. Cardiovasc Diagn Ther 2014, 4:245-262. 
4. Kasner SE, Chimowitz MI, Lynn MJ, Howlett-Smith H, Stern BJ, Hertzberg VS, Frankel MR, Levine SR, Chaturvedi S, Benesch CG, Sila CA, Jovin TG, Romano JG, Cloft HJ, for the Warfarin Aspirin Symptomatic Intracranial Disease (WASID) Trial Investigators: Predictors of ischemic stroke in the territory of a symptomatic intracranial arterial stenosis. Circulation 2006, 113:555-563.

5. Wang Y, Liu L, Wang Y, Soo Y, Pu Y, Wong KS: A multicenter study of the prevalence and outcomes of intracranial large artery atherosclerosis among stroke and TIA patients in China [abstract]. Stroke 2012, 43:A120.

6. Liebeskind DS, Cotsonis GA, Saver JL, Lynn MJ, Turan TN, Cloft HJ, Chimowitz Ml: Collaterals dramatically alter stroke risk in intracranial atherosclerosis. Ann Neurol 2011, 69:963-974.

7. Liebeskind DS, Cotsonis GA, Lynn MJ, Cloft HJ, Fiorella DJ, Derdeyn CP, Chimowitz MI, on behalf of the SAMMPRIS Investigators: Collaterals determine risk of early territorial stroke and hemorrhage in the SAMMPRIS trial. Stroke 2012, 43:A124

8. Min JK, Koo BK, Erglis A, Doh JH, Daniels DV, Jegere S, Kim HS, Dunning AM, DeFrance T, Lansky A, Leipsic J: Usefulness of noninvasive fractional flow reserve computed from coronary computed tomographic angiograms for intermediate stenoses confirmed by quantitative coronary angiography. Am J Cardiol 2012, 110:971-976.

9. Koo BK, Erglis A, Doh JH, Daniels DV, Jegere S, Kim HS, Dunning A DeFrance T, Lansky A, Leipsic J, Min JK: Diagnosis of ischemia-causing coronary stenoses by noninvasive fractional flow reserve computed from coronary computed tomographic angiograms: results from the prospective multicenter DISCOVER-FLOW (Diagnosis of Ischemia-Causing Stenoses Obtained Via Noninvasive Fractional Flow Reserve) study. J Am Coll Cardiol 2011, 58:1989-1997.

10. Morris PD, Ryan D, Morton AC, Lycett R, Lawford PV, Hose DR, Gunn JP: Virtual fractional flow reserve from coronary angiography: modeling the significance of coronary lesions: results from the VIRTU-1 (VIRTUal Fractional Flow Reserve From Coronary Angiography) study. JACC Cardiovasc Interv 2013, 6:149-157.

11. Schirmer CM, Malek AM: Prediction of complex flow patterns in intracranial atherosclerotic disease using computational fluid dynamics. Neurosurgery 2007, 61:842-852.

12. Liebeskind DS, Fong A, Scalzo F, Derdeyn CP, Fiorella DJ, Cloft HJ, Chimowitz MI, Feldmann E: SAMMPRIS angiography discloses hemodynamic effects of intracranial stenosis: computational fluid dynamics of fractional flow. Stroke 2013, 44:A156.

13. Samuels OB, Joseph GJ, Lynn MJ, Smith HA, Chimowitz MZ: A standardized method for measuring intracranial arterial stenosis. AJNR Am J Neuroradiol 2000, 21:643-646.

14. Antiga L, Piccinelli M, Botti L, Ene-lordache B, Remuzzi A, Steinman DA: An image-based modeling framework for patient-specific computational hemodynamics. Med Biol Eng Comput 2008, 46:1097-1112.

15. Batchelor GK: An Introduction to Fluid Dynamics. Cambridge: Cambridge University Press; 1967.

16. Min JK, Berman DS, Budoff MJ, Jaffer FA, Leipsic J, Leon MB, Mancini GBJ Mauri L, Schwartz RS, Shaw LJ: Rationale and design of the DeFACTO (Determination of Fractional Flow Reserve by Anatomic Computed Tomographic AngiOgraphy) study. J Cardiovas Comput Tomogr 2011, 5:301-309.

17. Chimowitz MI, Lynn MJ, Howlett-Smith H, Stern BJ, Hertzberg VS, Frankel MR, Levine SR, Chaturvedi S, Kasner SE, Benesch CG, Sila CA, Jovin TG, Romano JG: Comparison of warfarin and aspirin for symptomatic intracranial arterial stenosis. N Engl J Med 2005, 352:1305-1316.

18. Chimowitz MI, Lynn MJ, Derdeyn CP, Turan TN, Fiorella D, Lane BF, Janis LS, Lutsep HL, Barnwell SL, Waters MF, Hoh BL, Hourihane JM, Levy El, Alexandrov AV, Harrigan MR, Chiu D, Klucznik RP, Clark JM, McDougall CG, Johnson MD, Pride GL, Jr., Torbey MT, Zaidat OO, Rumboldt Z, Cloft HJ: Stenting versus aggressive medical therapy for intracranial arterial stenosis. N Engl J Med 2011, 365:993-1003.

19. Weber R, Kraywinkel K, Diener HC, Weimar C, German Stroke Study C: Symptomatic intracranial atherosclerotic stenoses: prevalence and prognosis in patients with acute cerebral ischemia. Cerebrovasc Dis 2010, 30:188-193.
20. Liebeskind DS, Kosinski AS, Saver JL, Feldmann E, for the SONIA Investigators: CT angiography in the Stroke Outcomes and Neuroimaging of Intracranial Atherosclerosis (SONIA) study [abstract]. Stroke 2007, 32:477.

21. Feldmann E, Wilterdink JL, Kosinski A, Lynn M, Chimowitz MI, Sarafin J, Smith HH, Nichols F, Rogg J, Cloft HJ, Wechsler L, Saver J, Levine SR, Tegeler C, Adams R, Sloan M, the SONIA Trial Investigators: The Stroke Outcomes and Neuroimaging of Intracranial Atherosclerosis (SONIA) trial. Neurology 2007, 68:2099-2106

22. Leng $X$, Wong KS, Liebeskind DS: Evaluating intracranial atherosclerosis rather than intracranial stenosis. Stroke 2014 45:645-651.

23. Liebeskind DS, Cotsonis GA, Saver JL, Lynn MJ, Cloft HJ, Chimowitz MI, Warfarin-Aspirin Symptomatic Intracranial Disease Investigators: Collateral circulation in symptomatic intracranial atherosclerosis. J Cereb Blood Flow Metab 2011, 31:1293-1301.

24. Scalzo F, Hao Q, Walczak AM, Hu X, Hoi Y, Hoffmann KR, Liebeskind DS: Computational hemodynamics in intracranial vessels reconstructed from biplane angiograms. In Advances in Visual Computing, Part III, Volume 37. Edited by Bebis G, Boyle R, Parvin B, Koracin D, Chung R, Hammound R, Hussain M, Kar-Han T, Crawfis R, Thalmann D, Kao D, Avila L. Berlin Heidelberg: Springer; 2010:359-367. Lecture Notes in Computer Science.

25. De Bruyne B, Sarma J: Fractional flow reserve: a review. Heart 2008, 94:949-959.

26. Westerhof N, Lankhaar JW, Westerhof BE: The arterial Windkessel. Med Biol Eng Comput 2009, 47:131-141.

27. Douglas AF, Christopher S, Amankulor N, Din R, Poullis M, Amin-Hanjani S, Ghogawala Z: Extracranial carotid plaque length and parent vessel diameter significantly affect baseline ipsilateral intracranial blood flow. Neurosurgery 2011, 69:767-773.

28. Min JK, Leipsic J, Pencina MJ, Berman DS, Koo BK, van Mieghem C, Erglis A, Lin FY, Dunning AM, Apruzzese P, Budoff MJ, Cole JH, Jaffer FA, Leon MB, Malpeso J, Mancini GB, Park SJ, Schwartz RS, Shaw LJ, Mauri L: Diagnostic accuracy of fractional flow reserve from anatomic $C T$ angiography. JAMA 2012, 308:1237-1245

\section{Submit your next manuscript to BioMed Central and take full advantage of:}

- Convenient online submission

- Thorough peer review

- No space constraints or color figure charges

- Immediate publication on acceptance

- Inclusion in PubMed, CAS, Scopus and Google Scholar

- Research which is freely available for redistribution 